\title{
Exploration and Practice of "Four - mode and Five - step” Ecological Classroom Teaching Mode
}

\author{
Shixiong Yang, Renjun Guo \\ Chongqing Minority Middle School, Congqing, China, 400082
}

Keywords: Ecological Classroom, Teaching Exploration, Classroom Teaching

\begin{abstract}
In order to achieve the goal of "school-based urban and rural coordination demonstration junior middle school, Chongqing national junior middle school education window school", in recent years, our school teachers around the curriculum reform, focusing on four-step "ecological classroom" teaching mode, In the study, research practice, practice reflection, update the educational philosophy and teaching strategies, optimize teaching methods and teaching methods, self-strengthening and education Peach Lee, Li Shangrun Shangxing life, practice our "one two three four five" school thinking.
\end{abstract}

\section{The Connotation and Characteristics of Ecological Classroom}

The Connotation of Ecological Classroom. Classroom is a special ecology, with ecological vision of every ecological factor in the classroom both biological and non-biological both material and spiritual, both dynamic and static, these factors are interdependent, Harmonious symbiosis to form a teaching atmosphere. The relationship between teachers and students, between students and students and their interaction with the teaching environment is a benign development of the dynamic balance between people and the environment in classroom teaching.

To the ecological vision, attitude and methods to observe, think, analyze the classroom. In the classroom teaching to adhere to the student development as the main body of all ecological factors between the organic combination and coordination of movement, and then produce mutual encouragement, participation, questioning the learning atmosphere, in the teaching of teachers and students to achieve common development, sustainable development and harmony development of. Ecological classroom from the cognitive field to the field of life, concerned about human nature, highlight the development of teachers, students, teaching environment, the process of dialogue.

The ecological classroom of our school focuses on every ecological factor in the classroom with an ecological perspective, so that every student has become the best self, so that each teacher has become the most happy education as the goal, under the guidance of teachers "Learning" as the center, with the preview, display, feedback as the basic process to guide the case, group building, classroom evaluation as the starting point of the classroom.

The Basic Characteristics of Ecological Classroom. The ecological classroom is the dialectical thinking of the relationship between man and nature, which is the core of the harmony between man and nature. The ecological classroom is characterized by the following basic characteristics:

Unity of diversity and symbiosis. In the process of exploration and transformation of nature, mankind needs to always treat all things in nature with a broad vision, mind and vision. Do not sacrifice the richness and diversity of nature for the immediate and local interests. In the classroom teaching is the same and teachers and students are rich individuals with diversity. Diversity is an external manifestation of the richness of classroom ecosystems. In the classroom teaching, recognize the diversity of students, to allow and pay attention to the protection of classroom teaching students' personality. Ecological classroom should follow the individual's life development rules and principles, to promote students' lives to a more complete and harmonious, reflecting the return of the nature of education, into the student's life world, to promote the harmonious operation of the various aspects of classroom teaching, Rich and varied environment in common development, to achieve diversity and symbiosis of unity. 
Unity of integrity and dynamics. Ecology believes that any creature is composed of various parts of the orderly, stable and complete life community. Traditional classroom teaching requires teachers to teach and learn the students in the classroom to complete the scheduled lesson plans. In fact, our teaching situation around the flow of "information flow" is always in constant development and change, the more pre-class settings, the students may be less free space. The ecological classroom regards the students as the education of the body, as the first resource of teaching, for them to establish a free, harmonious, rich personality of the independent learning environment, the teaching methods, means and teaching organization according to the teaching needs of flexible choice and combination so that the students' cognition, emotion, attitude and values are coordinated and developed in a coordinated manner so that the material, energy and information in the classroom are transformed from unbalanced to balanced, from new balance to new unbalanced cycles, so that the effectiveness of classroom teaching and quality of life continue to be improved to achieve the overall development of the classroom as a whole and dynamic.

The unity of openness and interactivity. Ecological classroom as one of the components of nature is an open system, but also a dynamic interaction with the system. Openness means that the interrelationships between the elements inside and outside the system are not just interactions within an independent system, but also a variety of connections with the environment. Therefore, the independence of the independence and the unity of the interaction is the existence of ecological classroom system. Ecological classroom as an open ecosystem, there are "material", "energy", "information" access and exchange, has its own energy interaction law. Students in the classroom to obtain knowledge at the same time, to consider their cognitive ability to accept the psychological ability to ensure that students can assimilate new knowledge, so that the old and new knowledge to establish interrelationship. In the ecological classroom teaching, the development of students should not only stay in the level of knowledge teaching, ability training, but also a life for the development of teachers and students, and the interaction between the teaching environment activities, teachers and students in this process to enjoy the joy of the growth of life process. Therefore, in the classroom teaching, attention to the value of life, improve the quality of thinking, the formation of teachers, students of the development and interactive development of the ecological chain, between teachers and students and their teaching environment and free dialogue between the ecological development field, the establishment and formation ecological classroom harmonious development of the organic life to achieve the openness of ecological classroom and interactive unity.

The unity of finite and infinite. Nature implies that the material wealth seems to be infinite, people only to the natural unlimited access, and the lack of protection and construction of natural consciousness. In fact, as opposed to meet the needs of schools, teachers, parents, students as a natural ecological environment, the value of resources is limited, the students can be infinitely filled with knowledge of the container, excessive inculcation, infinite supply, easily lead to Students' interest in learning and other spiritual resources near the "exhausted" state. The development of human potential can be endless, but this blind development concept forget that people are the product of nature, human development should not only comprehensive, personalized, should also be sustainable, lifelong development, unlimited to students exhaustive intelligent mining will be as dangerous as the devastating use of the earth's resources. Students as an independent self-contained life, with its own development laws and characteristics, ignoring the individual needs of students and the development of development and over-development, will pay more than the destruction of natural ecological cost. At the same time, in terms of people's understanding, the development potential of students is infinite, the process of human understanding is a dialectical negation of the development process, knowledge is a reusable and without loss of unlimited resources and pollution-free resources. With the growth of students 'lives, students' awareness is constantly enrich and develop, learning is a lifelong behavior, cognitive development is also a lifelong pursuit. Therefore, the ecological classroom teaching should not only protect the students' cognitive needs, but also continue to promote the generation of new cognitive students, classroom teaching knowledge to achieve the limited and unlimited unity.

Unification of differences and standards. In the teaching of ecological classroom, we should pay 
special attention to the question of "human nature", respect the differences, diversity and uniqueness of people, pay attention to the unique feelings, experiences, subjectivity and potential development of students, and meet the reasonable needs of students. At the same time, students' world outlook and values are being formed. Teachers should not only respect their choices according to their individual differences, but also guide them according to certain rational "standards" so as to continuously improve students' quality of life and develop students' rigor of life attitude and sense of responsibility and teachers are constantly constraining their own to the correct direction of development. This rational "standard" embodies a certain truth and human consensus, but also reflects the norms of modern education, guiding role. If there is no truth, the law of exploration, there is no law based on the development of teaching standards, the classroom will fall into the disorder, chaos abyss any "humanities" things are out of the question. Ecological classroom order, sustainable development needs and also have "law", "consensus", "standard" to follow. It is with this "rational spirit", classroom teaching to overcome the people as a member of the animal sector narrow vision, beyond the perceptual limitations, so that their own scientific, systematic, theoretical thinking of continuous evolution and development, to avoid the other animals So completely dominated by the fate of nature, which is to follow the ecological classroom differences and the standard of the important law of unity. Differences are standard differences, and standards are also based on differences. Classroom teaching requires both differences and rules and rules of truth, truth. Of course, the emphasis on standards, not as traditional, with the standard hegemony to suppress the difference, the classroom cannot only mean textbooks, teachers, "standard" without students "multiple experience", "multiple understanding."

\section{The Path and Methods of Implementation of Curriculum Reform}

A culture. Create an open curriculum culture. In a school, the spiritual culture is the soul; the system culture is the guarantee; the curriculum reform culture is the core; the environment culture wants to educate; the embodiment of the behavior culture; the open culture can invigorate; the characteristic culture can innovate. Create a curriculum reform culture, class culture, campus culture, in the belief in power, cohesion, action to build schools, class ecology.

Two fulcrums. First, the teacher's education and teaching ideas and understanding of the way students grow their lives, study the curriculum, grasp the teaching materials, business quality; the second is to develop students' self-learning ability, scientific learning methods and good habits.

Three driven. Principals led, the theme drive, typically driven.

Four elements: teachers, students, teaching materials, methods are four elements of classroom ecology, determine classroom efficiency.

Five master: the first team of the establishment and construction. The second grips lead the way to prepare and use: the third three-level modeling: school macro mode, the development of various classes for the various types of classroom flexible model, the teacher characteristics style model. The fifth grips according to the different disciplines, the appropriate layout of operations.

Six relationships. Teachers and students, teachers and teaching materials, teachers and methods, students and teaching materials, students and methods, teaching materials and methods.

Seven strategies: listening lessons, lessons learned (school research, find problems), training and learning, change the concept (concept change, open thinking), based on teachers, boost development (method to lead, teach what) (Evaluation in place, is the protection), build a platform to boost the development (the results show that the development of the project, the development of the model, the development of the model, Highlights reports) ".

\section{Classroom Teaching Strategies}

Low starting point, fine target, slow slope, dense steps, ground feedback, heavy emotions, so that each student can get the best development he can achieve, so that each student on the basis of the original (spiritual quality, moral cultivation, academic performance, thinking ability, behavior habits and hobbies, etc.) qualitative improvement. 


\section{Classroom Teaching Model}

Common Mode of Classroom Teaching. Four modules: fun guide $\bullet$ link module, autonomous learning • independent module, cooperative learning • inquiry module, clearance detection • evaluation module.

Five steps: import $\rightarrow$ self-study (single school, school, group) $\rightarrow$ display (small display, big show) $\rightarrow$ feedback $\rightarrow$ evaluation.

Mode Operation. According to the subject, class, content, hours of the four modules on the dynamic combination of class.

Fun guide - Link module: scenario creation, stimulate interest; student lectures, listening and speaking training; explain the demonstration, experimental exploration and so on.

Autonomous learning • Single module and cooperative learning • Exploring modules: There are five steps in the class:

Import $\rightarrow$ self-study (single, school, group) $\rightarrow$ display (small display, big show) $\rightarrow$ feedback $\rightarrow$ evaluation.

The first step into the introduction: teachers explain what students do, how to learn (very critical, to teach methods, to ask, students use two-color pen to mark their own learning confusion).

The second step of self-study: students self-learning (single school, school, group); according to the study case self-learning, to find learning confusion; around the confusion on the school; teacher inspection, check the progress of self, the results, according to the group to complete the situation, group.

The third step shows: students show and question (small display, big show). To the group as a unit, under the organization of the group leader, "show" learning results, that the "small show"; teachers check the process of exposure problems exposed, teachers show a small show based on common problems, guide the class " " (Display: talk about speech, blackboard on the blackboard, multimedia display platform)

The fourth step feedback: for students to show by the students or teachers to ask, comment or teacher to explain, stressed, blackboard, demonstration.

The fifth step evaluation: timely evaluation of the group to score.

Mode Operation Instructions. Operational principles. Group construction is the key, guide the case is the starting point, "soldiers and soldiers", "soldiers training", "soldiers" is the method, the comment is the essence of evaluation is a means. Class to complete the "six transfiguration", change teachers "speak" for students to "do", so that students in the "do" thinking, take the initiative to explore; change the "book" to teach "learning", change irrigation knowledge as a guide to learn; Students focus on the work to focus on lesson preparation; teachers walk down the podium to participate in the students took to the podium display; teachers under the sea selected exercises, students surfing exploration innovation.

To promote the "three moving", that is, brain, hands-on, and so on, that is, the main body, move to achieve the "three", that is, learn, will learn, will use; development of "four-dimensional", that is, cognitive, emotional, skills, experience.

Four-mode dynamic combination. This is based on the general pattern of the ecological classroom according to the contents of a lesson to design. As the school, discipline, class, the difficulty of learning the difference in the design of the case and the classroom session will be adjusted. Such as English in the self-learning, teachers should first show students words; such as language sometimes teachers should first read the text; if the learning content is more than two hours, you can focus on the first lesson, the first two modules, But the knowledge points are more, but also the first, second and third modules to implement the cycle (parallel cycle or spiral rise). If the learning content is only one class, but the knowledge points are more.

Each module time allocation problem. As the subjects, text content and learning different, the link time is difficult to determine, can only make a general time preset. Learned $\bullet$ Linked modules for 2-4 minutes; autonomous learning - independent modules for 5-10 minutes; and cooperative learning • inquiry module for 20 minutes; clearance detection module for 6 minutes. The specific circumstances of the classroom as a real adjustment accordingly. 
Teachers control the skill of the classroom. The return of the classroom to the students does not mean that the simple "territorial transfer" does not mean that the teacher does nothing, but to the teacher put forward higher requirements, students, after all, students, they are also in all aspects of "tender." In the effective teacher-student interaction, the default learning goal is often due to student active, creative thinking and generates new learning goals. Play the main role of students, absolutely cannot do without the leading role of teachers. Intensive "group participation", "large capacity" content, diversification of learning methods, more appropriate guidance, control of the whole teaching links, teachers' "goblet", "from the turn", and "spot response", "improvisation Play "the ability to be crucial. In the key points of knowledge and the key points of student thinking and "random dial" play a "inspired" role, leading the role of teachers is teaching wisdom.

Students show. The essence of the ecological classroom is mainly reflected in the students' classroom presentation. Classroom presentation is a platform for students to learn to communicate and exchange show is the main theme of the classroom, the student's action throughout the entire classroom. Through the student's mouth, hands, brain, both after the group discussion students in the blackboard on the written display, including students on stage lectures and student interaction questioning the process of a variety of display activities to show the results of preview to achieve active thinking, exercise courage, cultivate the ability to shape the purpose of personality. Teachers should have the full participation of students awareness to mobilize more students learning enthusiasm, so that students unfettered "move", arbitrary "say", in the classroom zero interference state initiative to learn to teach, teachers should encourage Students are boldly articulating their opinions and opinions different from others. But the organization is not good there may be "out of control" situation fail to achieve the desired effect. For example, the show spread, delay time; excellent singing "one-man show", other students by the cold; do not show the students do not care about the show, classroom atmosphere lonely.

\section{Reference}

[1] Li Sen. On the Ecological Nature, Characteristics and Functions of Classroom [J]. Educational Research. 2005 (10) 